\title{
Elder abuse and neglect in Bangladesh: understanding issues, associated factors and consequences
}

\author{
SHEKH FARID ${ }^{1,2, A-F}$ \\ ${ }^{1}$ BRAC, BRAC Centre, Dhaka, Bangladesh \\ ${ }^{2}$ Institute of Social Welfare and Research, University of Dhaka, Bangladesh
}

A - Study Design, B - Data Collection, C - Statistical Analysis, D - Data Interpretation, E - Manuscript Preparation, F - Literature Search, G - Funds Collection

\begin{abstract}
Summary Background. Fewer studies have attempted to address elder abuse and neglect in Bangladesh despite its widespread prevalence and fatal consequences.

Objectives. To collect qualitative facts concerning the nature of elder abuse and neglect in Bangladesh and to find out the causes and impacts of this malpractice.

Material and methods. The study categorized older people into ten broader classes and selected four old persons purposively under each category for an in-depth case study. In addition, Focus Group Discussion, Key Informants Interview and observational methods were also used to draw supplementary data.

Results. The results show that all old persons interviewed, irrespective of socio-economic status, came up against varying degrees of abuse and neglect by their families, relatives and communities that resulted in their physical ill-health and mental distress. Financial and physical abuses were found more frequent among poor and weaker sections, whereas psychological abuse appeared as severe among those belonging to the middle and affluent classes. Families having strong religious practices and a long tradition of taking care of the elderly were less subjected to elder mistreatment. As is revealed, along with various other factors, degradation of moral and religious values, new family structure and the lower socio-economic status of old people were associated with the maltreatment they faced.

Conclusions. Socio-economic insecurity and a poor institutional mechanism for old persons cause a higher incidence of elder abuse and neglect in Bangladesh, which calls for immediate action from all levels.

Key words: ageing, elder abuse, Bangladesh, aged.
\end{abstract}

Farid S. Elder abuse and neglect in Bangladesh: understanding issues, associated factors and consequences. Fam Med Prim Care Rev 2017; 19(2): 123-127, doi: https://doi.org/10.5114/fmpcr.2017.67865.

\section{Background}

The rapid growth in the proportion of people aged 60 and above is creating an unprecedented level of global demographic revolution [1], and Bangladesh is no exception from this process of population ageing. The latest population census of Bangladesh (2011) showed that the aged population account for $7.4 \%$ of the total population. The proportion is projected to almost triple to $21.5 \%$ of the total population by 2050 [2]. As the proportion of aged population grows, so does the severe but hidden problem of elder abuse and neglect. Elder abuse, also called elder mistreatment or elder maltreatment, includes psychological, physical and sexual abuse; neglect (caregiver neglect, self-neglect); and financial exploitation [3]. Abuse and neglect of the elderly is no longer an isolated family violence, but rather it is recognized as a human and civil rights issue [4] and a global public health concern. While there is little information regarding the extent of elder mistreatment, especially in developing countries, the World Health Organization estimates that 1 out of 10 older people experience abuse each month [5]. Despite having serious and devastating consequences on both the elderly and society [6-8], the issue continues to be a taboo, mostly underestimated and ignored by societies across the world [9]. The prevalence rate of elder abuse and neglect in developing countries, including Bangladesh, where "most of the elderly people suffer from some basic human problems, viz. poor financial support, senile diseases and absence of proper health and Medicare facilities, exclusion and negligence, depri- vation and socio-economic insecurity [10]", is appallingly high. Despite its widespread prevalence, the issue is not reflected in our policy, and the victims hardly find any institutional mechanism to seek a remedy. Although several studies focused on the issue in the global context, given the socio-cultural situation of Bangladesh, the issue is poorly understood. To be able to respond adequately to the problem of elder abuse and neglect in Bangladesh, it is essential to identify the problem and to examine its magnitude. Hence, studying the nature and all related aspects of elder abuse and neglect is significant. It has, therefore, become inevitable to address the issue of elder abuse and neglect and to protect the rights of this increasing proportion of the population.

\section{Objectives}

The study aimed to analyze the nature of elder abuse and neglect in Bangladesh and to identify associated factors, persons involved and the impacts of this malpractice.

\section{Material and methods}

As the study was descriptive in nature, it employed a qualitative method of social research. Some previous studies also used the same method to find out facts concerning similar issues $[7,9]$. Regarding the definition of elder abuse and neglect, the study accepted the definition given by the Action on Elder 
Abuse (UK) in 1995, as adopted by the World Health Organization-Center for Interdisciplinary Gerontology (WHO-CIG): "a single or repeated act or lack of appropriate action, occurring within any relationship where there is an expectation of trust which causes harm or distress to an older person" [9]. At first, the study purposively selected two areas of Bangladesh - Dhaka City and Chatkhil Upazilla under the Noakhali District - as a study area. It categorized older people (aged $\geq 60$ ) into ten broader classes and selected 4 old persons from each class for an in-depth case study through using the purposive sampling technique (small, non-random Judgmental sample). The categories included rural poor, rural middle class, rural affluent, urban poor, urban middle class, urban rich, handicapped, widow, single male and resident of nursing home for the elderly. For each category, two were male and two were female, except the four males for the 'single male' category and four females for the 'widow' category. These categories and the criteria of identification of elder abuse and neglect have been derived from the researcher's knowledge and observation, as well as from literature found relevant to the issue [1-12, 18-26]. The respondents were from diverse professionals, and only those who agreed to provide information were included in the sample. 5 key persons ( 3 academic scholars and two practitioners) were also selected purposively for a Key Informants Interview (KII). Along with this, 14 older people (7 from urban areas and 7 from rural areas) were also selected purposively for conducting two Focus Group Discussions (FGDs). To this end, a moderation sheet was used as a data collection tool. Data was also collected by using noncontrolled observational techniques as a detached emissary, rather than becoming actively involved with them. All interviews were face-to-face, and an interview guideline, comprising both closed and open-ended questions, written in the Bengali language, was used in each interview. The interviews ranged from 40 to 60 minutes. Furthermore, the researcher recorded the data using a digital recorder and notes. After collection of raw data, it was translated into English and analyzed using the thematic approach along with graphical presentation. The thematic approach of data analysis was used, as it is recognized as the most common [13] and foundational [14] method of analysis of qualitative data. The method emphasizes the content of a text: 'what' is said more than 'how' it is said; the 'told' rather than the 'telling' [15]. The categories and analytical codes have been drawn in alignment with the set objectives. The study followed the ethical guidelines provided by Berg [16] and Miles and Huberman [17]. The duration of the study was from September 2015 to April 2016.

\section{Results}

\section{Nature of elder abuse and neglect in Bangladesh}

The study found that all older persons interviewed, irrespective of socio-economic class, had experienced, more or less, abuse and neglect. The mistreatment mostly took place within the families. In some cases, their spouses were supportive, but some reported that they faced abuse and neglect by their spouse in disputes. As was observed, families following religious practices and holding strong familial values were less subjected to elder mistreatment. But some older people reportedly experienced mistreatment in spite of following religious practices in their families. Whereas older people with economic security and social acceptance were less likely to face continuous abuse and neglect, older people with disabilities, socio-economic insecurity and those having low economic contribution to their families were at greater risk of facing frequent abuse and neglect. The forms of mistreatment elderly people reportedly faced are illustrated in Figure 1. Although the forms and nature of the mistreatment were not common to everyone, negligence by others accused were prevalent to everyone.

The incidence of sexual abuse was lower, as only one participant in the FGD reported this form of abuse. Psychological abuse and negligence were found to be prevalent among all classes, but physical and financial abuses were severe among poor and older people with disabilities. Likewise, older persons who lost their partners were at greater risk of experiencing severe abuse and neglect. Some old persons from the affluent class also claimed that their sons fraudulently took their money away. A common form of emotional abuse found in rural areas was being called 'Bura or Buri' (local words meaning 'old', usually used to underestimate someone). Older people belonging to the urban middle class were more vulnerable, as they could hardly afford anyone to take care of them.

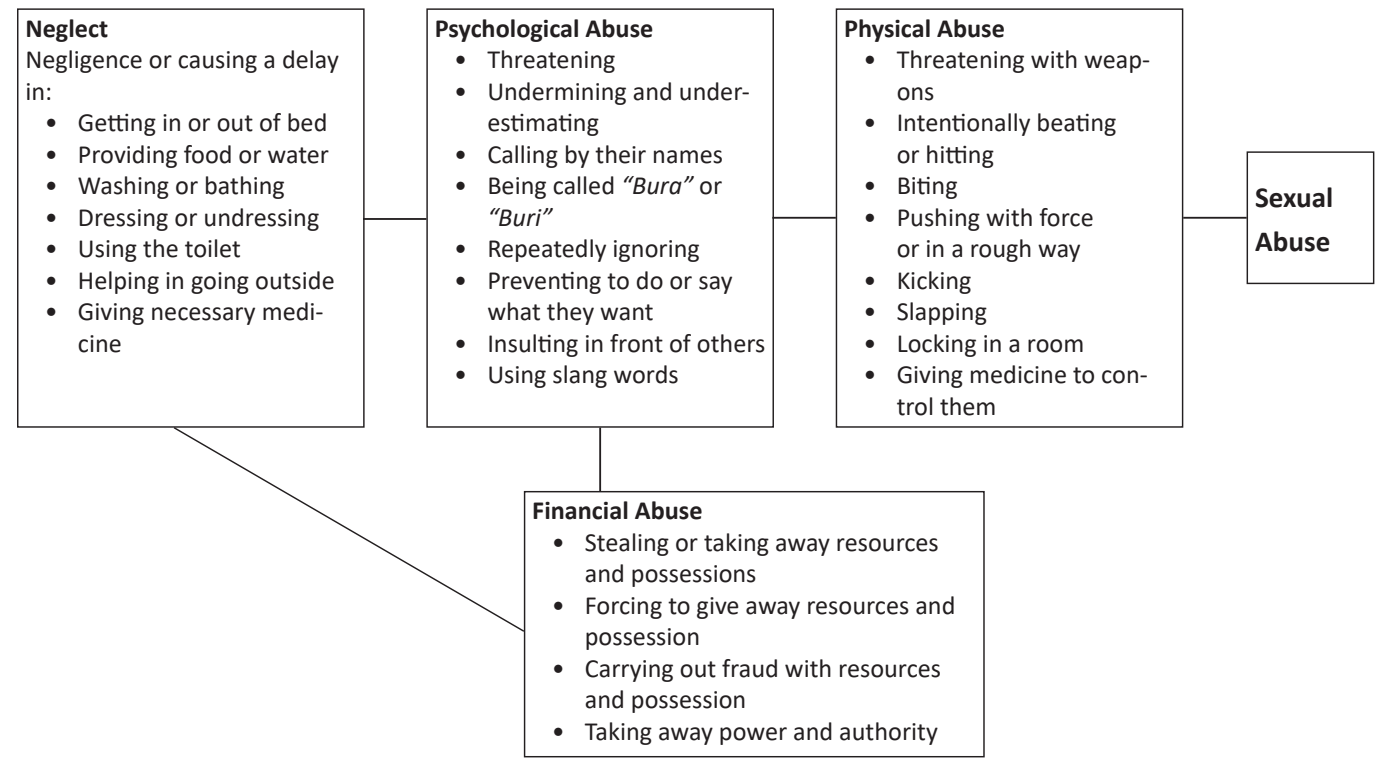

More 


\section{Persons involved}

The respondents were asked about the persons they experienced abuse and neglect from. Almost all of them experienced abuse and neglect from their family members (spouse, sons, daughters, grandchildren), most reportedly, by their daughters-in-law. Figure 2 illustrates that they experienced abuse and neglect by those they come in contact with most. Their relatives and people within the community were also found to be guilty of maltreatment. Moreover, some accused their friends and fellow older people, the paid caregiver and the organizations (including the paid caregiver in an institutional setting) of mistreatment. Some old persons, mostly in urban areas, reported that they experienced abuse by some unknown person while going outside.

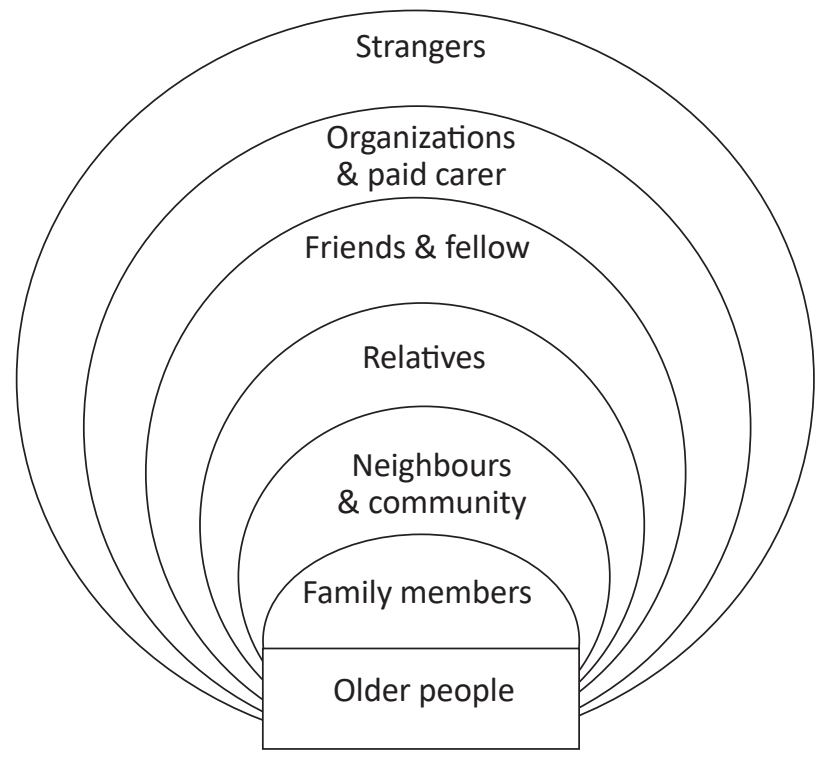

Figure 2. Persons involved in elder abuse and neglect in Bangladesh

\section{Causes}

The study attempted to identify factors causing elder abuse and neglect in Bangladesh. Typically, they did not seek for redress when they faced abuse and neglect, and a majority of cases went unreported, which triggered the incidence to be taken place further. Figure 3 depicts how some external factors, most noticeably, the lower socio-economic status of older persons, the new family structure of a single-family system, inadequate institutional mechanism and degradation of moral and religious values, caused the incidence to occur. Sometimes, these external factors resulted in the dependency of the older persons on others, psychological distress and socio-economic insecurity, which subsequently led to elder mistreatment. Although some family members claimed that the older people are themselves responsible for the maltreatment they face, the study observed that the external factors mentioned earlier caused older people to develop psychological illnesses, which, in turn, made their families, neighbors and others manifest abusive behavior.

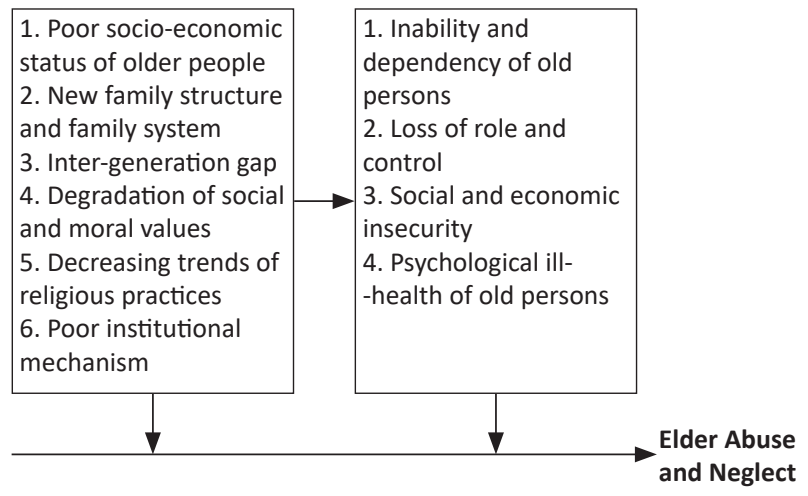

Figure 3. Factors causing elder abuse and neglect in Bangladesh

\section{Impact}

Elder abuse and neglect has devastating consequences, both on the older adults and on society. Figure 4 illustrates the impacts of abuse and neglect in Bangladesh both on the older persons and on larger society. Many older people reported that they had financial loss because of the financial abuse they faced and because of the treatment they needed in response to mistreatment. Malnutrition of old people was reportedly found to be the most prevalent impact of abuse and neglect. Some old persons were found suffering from diseases, such as diabetes, tooth decay, increased bone or joint problems, digestive problems, heart problems, high cholesterol, headache, back pain, high blood pressure and other chronic diseases. They reported that these diseases were the result of the mistreatment they had experienced. Respondents in the KII also stated that in Bangladesh, most older people suffer from long-term diseases due to abuse and neglect. Moreover, the study observed psychological symptoms (Figure 4) resulting from maltreatment among the respondents. Many of them stated that it would have been better if they had died. Some of them were found helpless, regretting their former life with poor self-esteem and low self-confidence. In addition, some older people said that they became socially isolated after having quarrels with others. They did not talk to the old people despite their several attempts at reconciliation, and this happened only because they displayed a reaction after facing abuse and neglect. Furthermore, the study found

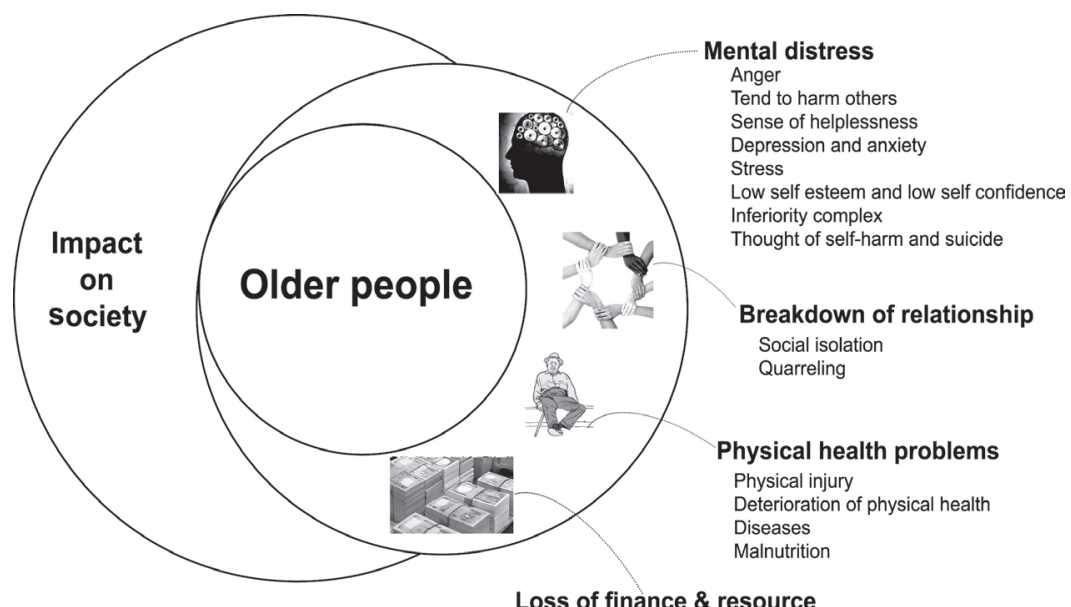

Figure 4. Impact of elder abuse and neglect in Bangladesh 
that elder mistreatment had a fatal impact, even on our society. It lowered the productivity of the victims and degraded our long tradition and values of respecting and taking care of the elderly.

\section{Discussion}

Elder abuse and neglect, although globally recognized as a violation of human rights, remains as a hidden form of interfamily conflict in many societies [18]. The estimate of the global prevalence of elder mistreatment is $10 \%$ [5]; some studies also show that estimates in community settings from Finland, Canada, the United States of America, the United Kingdom and the Netherlands range from 4-6\% [6]. The present study shows that the prevalence rate in Bangladesh is higher than that in developed countries, since it found that all respondents had reportedly experienced abuse and neglect. As the study selected a smaller sample for the in-depth case study, there is a need for a further population-based large-scale survey to discover an accurate prevalence rate. Given the cultural context of the country, sexual abuse was not pervasive, but the incidence of psychological abuse reached a point that no one considers this as violence. Physical abuse mainly takes place in rural areas and among the urban poor class. They are threatened and even beaten by others, mostly when they are in quarreling or in a dispute. Further studies also need to be carried out to find out the casual relationship between degradation of religious practices and elder abuse and neglect. Usually, family members (90\% approximately), spouses, close friends, paid caregivers, strangers/ /acquaintances and people within the community are involved in elder abuse and neglect $[7,19]$. In Bangladesh, most of elderly people accused their daughters-in-law of being involved in the mistreatment. It happens to be so because of a role dilemma whether they are obliged to abide by the long tradition of taking care of elderly family members. Apart from this, they also face abuse by their neighbors and people within the community. Usually, older persons who have a lower socio-economic status are at greater risk of being abused by their community members. Undermining, publicly insulting and being called 'Bura' or 'Buri' by older people of the same age or by younger people are reportedly common. In rural areas, incidences of this kind happen more frequently.

A number of cultural and socio-economic factors are associated with elder abuse and neglect, such as ageism, poverty, modernization and inheritance systems [6], devaluation of and lack of respect for older adults [20], as well as the lower socio-economic status of old people [21]. There are some external and internal factors associated with elder mistreatment. Poor institutional mechanisms, inadequate security measures for them, breakdown of extended family systems and social perception about ageing are some external factors that trigger elder abuse and neglect in Bangladesh. Our social safety-net programs are not adequate to ensure the security of people during their old age, which makes them dependent on others. Older people reported that the incidence of abuse and neglect increased when they distributed their property among their family members and became dependent on them.

In their study, Kujawska-Danecka et al. found that some symptoms of mental disorder - depression, anxiety, alcohol abuse, sleep disorder and post-traumatic stress disorder - are prevalent among people aged 65 years and older [22]. This is more severe among those who are undergoing frequent abuse and neglect. Studies suggest that the mistreatment of the elderly has fatal, costly and devastating consequences [23], which mostly manifest in psychosocial distress [24], significant adverse health outcomes [25] and a higher mortality rate [26]. Diseases and malnutrition were found to be a common outcome of elder abuse and neglect. Those older people who were undergoing frequent abuse and neglect showed a higher rate of depression, a feeling of inferiority and low self-esteem. Some of them wished to die than to live longer. Some old persons stated that they reacted with severe anger and shouting after facing mistreatment. Further research is also needed to assess if elder mistreatment is associated with a higher mortality rate in Bangladesh. Physicians, family doctors and other health professionals can play a vital role in identifying the physical and health outcome of elder abuse and neglect.

\section{Conclusions}

The prevalence of elder abuse and neglect in Bangladesh is higher than that in developed countries because of the lower socio-economic status of the old persons and the transition of society towards the new family system of a nuclear family. It has fatal, costly and serious consequences, both for the elderly and society. The government needs to increase support for the aged population, incorporating this issue in its policy and planning. A cross-cultural and population-based survey is also essential to find out the estimate of prevalence of elder abuse and neglect and to know the issue in details. Academicians, health professionals, social workers and other practitioners should come forward with multiple interventions to address the issue. Adequate social safety-net programs, institutional support both from the government and non-government sector and generation of mass awareness could be effective responses to the problem of abuse and neglect of the elderly.

Source of funding: This work was funded by the author's own resources. Conflict of interest: The author declares no conflict of interests.

\section{References}

1. Help Age International. The ageing and development report: a summary; poverty, independence and the world's older people. London: HelpAge International; 1999.

2. United Nations. World population prospects: the 2015 revision. New York: Population Division, Department of Economic and Social Affairs, United Nations Secretariat; 2015.

3. Dong X. Elder abuse: systematic review and implications for practice. J Am Geriatr Soc 2015; 63(6): 1224-1238.

4. World Health Organization. Abuse of elderly. Geneva: World Health Organization; 2002.

5. World Health Organization. World report on ageing and health. Geneva: World Health Organization; 2015.

6. Wolf R, Daichman L, Bennett G. Abuse of the elderly. In: Krug EG, Dahlberg LL, Mercy JA, et al., eds. World report on violence and health. Geneva: World Health Organization; 2002: 123-145.

7. Mowlam A, Tennant R, Dixon J, et al. UK study of abuse and neglect of older people: qualitative findings. London: Comic Relief and Department of Health; 2007.

8. Comijs HC, Penninx BWJH, Knipscheer KPM, et al. Psychological distress in victims of elder mistreatment: the effects of social support and coping. J Gerontol 1999; 54B(4): 240-245.

9. World Health Organization. A global response to elder abuse and neglect: building primary health care capacity to deal with the problem worldwide: main report. Geneva: World Health Organization; 2008.

10. Rahman ASMA. Aging. In: Banglapedia - The National Encyclopedia of Bangladesh. $2^{\text {nd }}$ ed. Dhaka: Asiatic Society of Bangladesh; 2012. 
11. Lachs MS, Pillemer KA. Abuse and neglect of elderly persons. N Engl J Med 1995; 332(7): 437-443.

12. Lachs MS, Pillemer KA. Elder abuse. N Engl J Med 2015; 373(20): 1947-1956.

13. Guest G. Applied thematic analysis. Thousand Oaks, California: Sage Publications; 2012

14. Holloway I, Todres L. The status of method: flexibility, consistency and coherence. Qualitative Res 2003; 3: 345-357.

15. Riessman CK. Narrative analysis. In: Jupp V, ed. The sage dictionary of social research methods. London, Thousand Oaks, NY: Sage Publications; 2006: 186-189.

16. Berg BL. Qualitative research methods for the social sciences. $4^{\text {th }}$ ed. Boston, London, Toronto, Sydney, Tokyo, Singapore: Allyn \& Bacon; 2001.

17. Miles MB, Huberman AM. An expanded sourcebook: qualitative data analysis. Thousand Oaks: Sage Publications; 1994

18. Podnieks E, Anetzberger GJ, Wilson SJ, et al. World view: environmental scan on elder abuse. J Elder Abuse Neg/ $2010 ; 22$ : 164-179.

19. Schiamberg L, Gans D. An ecological framework for contextual risk factors in elder abuse by adult children. J Elder Abuse Negl 1999; 11(1): 79-103.

20. American Psychological Association. Elder abuse \& neglect: in search of solutions. Washington, DC: American Psychological Association; 2012.

21. Gil APM, Kislaya I, Santos AJ, et al. Elder abuse in Portugal: findings from the first national prevalence study. J Elder Abuse Negl 2015; 27(3): 174-195.

22. Kujawska-Danecka H, Nowicka-Sauer K, Hajduk A, et al. The prevalence of depression symptoms and other mental disorders among patients aged 65 years and older - screening in the rural community. Fam Med Prim Care Rev 2016; 18(3): 274-277.

23. Acierno R, Hernandez MA, Amstadter AB, et al. Prevalence and correlates of emotional, physical, sexual, and financial abuse and potential neglect in the United States: the national elder mistreatment study. Am J Public Health 2010; 100(2): 292-297.

24. Yan E, Tang CSK. Prevalence and psychological impact of Chinese elder abuse. J Interpers Violence 2001; 16: 1158-1174.

25. Lachs MS, Williams CS, O'Brien S, et al. The mortality of elder mistreatment. JAMA 1998; 280(5): 428-432.

26. Dong $X$, Simon MA, Mendes-de-Leon $C$, et al. Elder self-neglect and abuse and mortality risk in a community-dwelling population. JAMA 2009; 302: 517.

Tables: 0

Figures: 4

References: 26

Received: 24.12 .2016

Revised: 02.02.2017

Accepted: 11.02 .2017

Address for correspondence:

Shekh Farid, MSS

BRAC, BRAC Centre

75 Mohakhali

Dhaka-1212

Bangladesh

Tel.: +8801866758492

Email: farid.s@brac.net, fariddu100@gmail.com 